Published in final edited form as:

J Am Chem Soc. 2012 October 10; 134(40): 16449-16451. doi:10.1021/ja305448w.

\title{
Direct Stereospecific Amination of Alkyl and Aryl Pinacol Boronates
}

\author{
Scott N. Mlynarski, Alexander S. Karns, and James P. Morken * \\ Department of Chemistry, Merkert Chemistry Center, Boston College, Chestnut Hill, \\ Massachusetts 02467
}

\begin{abstract}
The direct amination of alkyl and aryl pinacol boronates is accomplished with lithiated methoxyamine. This reaction directly provides aliphatic and aromatic amines, stereospecifically, and without preactivation of the boronate substrate.
\end{abstract}

\begin{abstract}
The tremendous range of transformations available to organoboron reagents renders these compounds strategically useful in organic synthesis. ${ }^{1}$ Amongst classes of boron compounds, boronic acid pinacol esters have received a great deal of attention from the catalysis community. While the stability of pinacol boronates facilitates their handling and allows them to be used under a broad range of reaction conditions, this stability comes at a price: many of the transformations that apply to electrophilic boranes are inaccessible with pinacol boronates. This feature especially pertains to the direct stereospecific amination of alkyl pinacol boronate esters. ${ }^{2}$ Whereas alkyl azides, chloroamines, and hydroxylamine derivatives are effective at amination of dichloroboranes, ${ }^{3}$ difluoroboranes, ${ }^{4}$ dialkylborinates, ${ }^{5}$ or trialkylboranes ${ }^{6}$, these reagents are unreactive with common boronic esters. ${ }^{7}$ In this report, we describe a solution to this problem and present a simple method for the direct stereospecific amination of alkyl pinacol boronates. To the best of our knowledge, this advance represents the only method for direct conversion of common pinacol boronates to alkylamine products.
\end{abstract}

As depicted in Scheme 1, stereoretentive amination of organoboron compounds is generally achieved by conversion of the trivalent boron reagent to a tetravalent boron "ate" complex derived from the amination reagent; subsequent 1,2-metallate rearrangement results in C-N bond formation and delivers the alkylamine product. ${ }^{8}$ We considered that the lack of reactivity between common amination reagents (i.e. alkyl azides) and pinacol boronates may be traced to ineffective association of the two reagents. Indeed, as alluded to above, one solution to the amination of boronate esters involves conversion of the boronate to a dichloroborane, difluoroborane or trialkylborane intermediate; the enhanced Lewis acidity of the resulting boron center enables association with the weak Lewis base and facilitates reaction. As an alternative to the preactivation described above, we considered that more nucleophilic amination reagents might overcome the decreased Lewis acidity of the pinacol ester, favoring ate complex formation, and perhaps allow direct amination of pinacol boronates.

*Corresponding Author: morken@bc.edu.

The authors declare no competing financial interest.

Supporting Information. Procedures, characterization and spectral data. This material is available free of charge via the Internet at http://pubs.acs.org. 
A study by Beak suggested that lithiated alkoxy amines, intermediates in the amination of alkyllithiums, might possess features appropriate to direct amination of alkyl boroantes. ${ }^{9}$ These reagents bear a labile alkoxide leaving group while still possessing an electron-rich nitrogen center. In a preliminary experiment (entry 1, Table 1), octylB(pin) was added to a pre-cooled $\left(-78^{\circ} \mathrm{C}\right)$ mixture of methoxyamine (1.0 equiv) and $n$-BuLi (1.0 equiv) in THF. After allowing the mixture to warm to ambient temperature, it was heated to $60{ }^{\circ} \mathrm{C}$ for 12 hours and then treated with $\mathrm{Boc}_{2} \mathrm{O} .{ }^{10}$ Under these reaction conditions, Boc-protected octylamine was generated in $41 \%$ yield; however, it was contaminated with $36 \%$ yield of Boc-protected butylamine, presumably generated by amination of butyllithium. Assuming that amination of butyllithium occured competively during the deprotonation of methoxyamine and was unavoidable, the use of increased amounts of the amination mixture was examined. As shown in entries 2 and 3, this strategy resulted in a significant improvement in product yields such that with 3 equivalents of $\mathrm{MeONH}_{2}$ and $n-\mathrm{BuLi}$, the amination of octylB(pin) occurred in $84 \%$ isolated yield. As shown by the remaining entries in Table 1, other bases are also able to affect amination, however, none surpass the efficacy of $n$-BuLi for this transformation. Also of note is that the amination conditions employ elevated temperature $\left(60^{\circ} \mathrm{C}\right)$ for 12 hours; at lower temperatures or for shorter reaction times, inferior yields resulted $\left(<5 \%\right.$ yield for entry 3 at $\left.22{ }^{\circ} \mathrm{C}\right)$.

Once optimized conditions were established for the boronate amination, the scope of this transformation was investigated. As shown in Table 2, the amination proved to be effective over a range of substrates. Notably, octylB(pin) was aminated on a scale relevant to preparative organic synthesis (1 gram) and proceeded equally well compared to smaller scale experiments. Also of note, benzyl ethers, silyl ethers, and acetals appear to be tolerated in the reaction (compounds 2-4). While nitrile functional groups are tolerated (compound 6), the yield is diminished with these substrates even though the starting material is completely consumed. It is also clear that the reaction is not perturbed by the presence of pendant alkenes, including those that are distal and those are adajcent to the boronate. Importantly, both cis- and trans- allylic boronates react cleanly without any observed isomerization of the olefin geometry (compounds $\mathbf{9}$ and 10). In terms of utility in stereoselective synthesis, it is also important that the amination operates on secondary boronates (compound 11); however, when tertiary substrates were employed (compound 12), the product was not detected.

The amination of pinacol boronates using methoxyamine is not limited to aliphatic substrates. Although prolonged reaction times are required, aryl boronates are also suitable substrates producing aniline derivatives. This reaction represents a metal-free alterative to Chan-Lam-Evans couplings between boronates and ammonia. ${ }^{11}$ As depicted in Table 3, while steric encumbrance does not appear to have a significant effect on the efficiency of the amination (cf. 13, 15 and 22), the reaction appears to be much more sensitive to the electronic properties of the aryl ring. The observation that electron-rich substrates undergo amination more efficiently than electron-poor aryl-boronates (cf. 19 and 21) suggests that 1,2-metallate rearrangement is likely the slow step in the reaction sequence. Lastly, B(pin)substituted heterocycles (4-borylpyridine, 2-borylfuran, 3-borylfuran, and 3-borylthiophene) failed to give the amination product (data not shown).

In line with the mechanism proposed in Scheme 1, it may be anticipated that B N bond migration would be stereospecific and preserve the configuration at the migrating carbon atom. To test this hypothesis, boronate $(R)-\mathbf{2 3 a}$, prepared in $83 \%$ ee by copper-Me-DuPhos catalyzed hydroboration of styrene, ${ }^{12}$ was subjected to the amination reaction (equation 1). This transformation provided Boc-protected a-methyl benzylamine $\mathbf{2 3 b}$ in $83 \%$ enantiomeric excess and in the $(R)$ configuration. Thus, the amination is stereospecific and occurs with retention of configuration at carbon. In related experiments, amination of exo- 


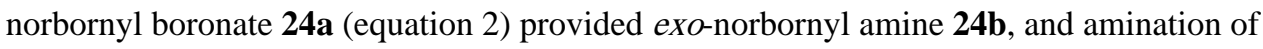
chiral aliphatic boronate $\mathbf{2 5 a}$ provided $\mathbf{2 5 b}$ with retention of configuration.
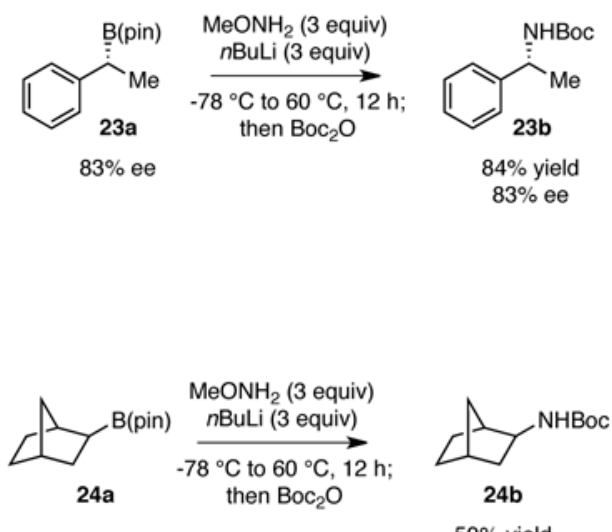

$50 \%$ yield

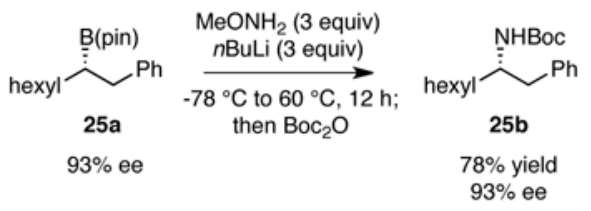

In conclusion, we report a stereospecific method for the direct conversion of alkyl and aryl pinacol boronates to amines. This transformation exhibits a broad substrate scope and can be run on gram scale without additional complications.

\section{Supplementary Material}

Refer to Web version on PubMed Central for supplementary material.

\section{Acknowledgments}

The NIH (GM-59471) is acknowledged for financial support; AllyChem $\left(\mathrm{B}_{2}(\mathrm{pin})_{2}\right)$ and BASF (pinacolborane) are acknowledged for donations of reagents. SNM is grateful for a LaMattina Fellowship.

\section{References}

1. Reviews: Brown HC, Kramer GW, Levy AB, Midland MM. Organic Syntheses via Boranes. WileyInterscienceNew York1975Brown HC, Singaram B. Acc Chem Res. 1988; 21:287.Crudden CM, Edwards D. Eur J Org Chem. 2003:4695.

2. For recent examples of aminations that are either not stereospecific, or where stereochemistry was not studied or not an issue, see: Ou L, Shao J, Zhang G, Yu Y. Tetrahedron Lett. 2011; 52:1430.Matsuda N, Hirano K, Satoh T, Miura M. Angew Chem Int Ed. 2012; 51:3642.Larrosa M, Guerrero C, Rodríguez R, Cruces J. Synlett. 2010:2101.Cazorla C, Métay E, Andrioletti B, Lemaire M. Tetrahedron Lett. 2009; 50:6855.Rucker RP, Whittaker AM, Dang H, Lalic G. J Am Chem Soc. 2012; 134:6571. [PubMed: 22469028] 
3. (a) Brown HC, Midland MM, Levy AB. J Am Chem Soc. 1973; 95:2394.(b) Brown HC, Salunkhe AM, Argade AB. Organometallics. 1992; 11:3094.(c) Carboni B, Vaultier M, Carrie R.

Tetrahedron. 1987; 43:1799.(d) Carboni B, Vaultier M, Carrie R. Tetrahedron Lett. 1988; 29:1279. (e) Hupe E, Marek I, Knochel P. Org Lett. 2002; 4:2861. [PubMed: 12182574]

4. (a) Matteson DS, Kim GY. Org Lett. 2002; 4:2153. [PubMed: 12074655] (b) Kim BJ, Matteson DS. Angew Chem Int Ed. 2004; 43:3056.(c) Bagutski V, Elford TG, Aggarwal VK. Angew Chem Int Ed. 2011; 50:1080.

5. Brown HC, Kim KW, Cole TE, Singaram B. J Am Chem Soc. 1986; 108:6761.

6. (a) Brown HC, Kim KW, Srebnik M, Singaram B. Tetrahedron. 1987; 43:4071.(b) Fernandez E, Hooper MW, Knight FI, Brown JM. J Chem Soc Chem Commun. 1997:171.(c) Fernandez E, Maeda K, Hooper MW, Brown JM. Chem Eur J. 2000; 6:1840. [PubMed: 10845644] (d) Brown HC, Heydkamp WR, Breuer E, Murphy WS. J Am Chem Soc. 1964; 86:3565.(e) Rathke MW, Inoue N, Varma V, Brown HC. J Am Chem Soc. 1966; 88:2870.(f) Hoffmann RW, Holzer B, Knopff O. Org Lett. 2001; 3:1945. [PubMed: 11405751] (g) Kabalka GW, Henderson DA, Varma RS. Organometallics. 1987; 6:1369.(h) Kabalka GW, Sastry KA, McCollum GW, Yoshioka H. J Org Chem. 1981; 46:4296.(i) Phanstiel IVO, Wang QX, Powell DH, Ospina MP, Leeson BA. J Org Chem. 1999; 64:803. [PubMed: 11674150]

7. For a recent strategy for stereospecific $\mathrm{C}-\mathrm{N}$ bond formation to construct alkylhydrazides and alkyldiazo compounds, see: Larouche-Gauthier R, Elford TG, Aggarwal VK. J Am Chem Soc. 2011; 133:16794. [PubMed: 21939203] For experiments addressing the direct amination of catecholbonates, see: Knight FI, Brown JM, Lazzari D, Ricci A, Blacker AJ. Tetrahedron. 1997; 53:11411.For a recent strategy for indolizidine synthesis involving stereospecific alkylborane amination, see: Pronin SV, Tabor MG, Jansen DJ, Shenvi RA. J Am Chem Soc. 2012; 134:2012. [PubMed: 22263967]

8. Reviews on 1,2 metallate rearrangments: Aggarwal VK, Fang GY, Ginesta X, Howells DM, Zaja M. Pure Appl Chem. 2006; 78:215.Thomas SP, French RM, Jheengut V, Aggarwal VK. Chemical Record. 2009; 9:24. [PubMed: 19243084]

9. Beak P, Basha A, Kokko B, Loo D. J Am Chem Soc. 1986; 108:6016. [PubMed: 22175366]

10. While the non-protected amine can be isolated, Boc protection allows separation of octylamine from butyl amine by silica gel chromatography.

11. (a) Monaco KL, Wang RP, Winters MP, Chan DMT. Tetrahedron Lett. 1998; 39:2933.(b) Katz JL, West TR, Evans DA. Tetrahedron Lett. 1998; 39:2937.(c) Lam PYS, Clark CG, Saubern S, Adams J, Winters MP, Chan DMT, Combs A. Tetrahedron Lett. 1998; 39:2941.

12. Noh D, Chea H, Ju J, Yun J. Angew Chem Int Ed. 2009; 48:6062. 


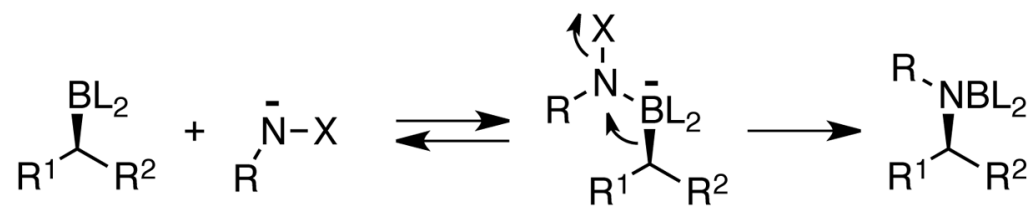

Scheme 1. 
Table 1

Amination of OctylB(pin). ${ }^{a}$

\begin{tabular}{|c|c|c|c|}
\hline $\begin{array}{c}\text { octyl-B(pin) } \\
\text { 1a }\end{array}$ & \multicolumn{2}{|c|}{$\frac{\begin{array}{l}\mathrm{MeONH}_{2} \\
\text { base }\end{array} \underset{-78{ }^{\circ} \mathrm{C} \text { to } 60{ }^{\circ} \mathrm{C}, 12 \mathrm{~h} ;}{\text { then } \mathrm{Boc}_{2} \mathrm{O}}}{}$} & \multirow{2}{*}{$\begin{array}{l}\text { R-NHBoc } \\
\text { 1b } \\
\text { yield (\%) }\end{array}$} \\
\hline entry & $\mathrm{CH}_{3} \mathrm{ONH}_{2}$ (equiv) & base (equiv) & \\
\hline 1 & 1.0 & $n-\operatorname{BuLi}(1.0)$ & 41 \\
\hline 2 & 2.0 & $n-\operatorname{BuLi}(2.0)$ & 72 \\
\hline 3 & 3.0 & $n-\operatorname{BuLi}(3.0)$ & 84 \\
\hline 4 & 3.0 & $\operatorname{MeLi}(3.0)$ & 48 \\
\hline 5 & 3.0 & $\mathrm{NaH}(3.0)$ & $<5$ \\
\hline 6 & 3.0 & KH (3.0) & $<5$ \\
\hline 7 & 3.0 & $\mathrm{~K}(\mathrm{O} t \mathrm{Bu})(3.0)$ & 16 \\
\hline 8 & 3.0 & $\mathrm{Li}(\mathrm{O} t \mathrm{Bu})(3.0)$ & $<5$ \\
\hline
\end{tabular}

${ }^{a}$ Reactions were conducted as described in the text. The percent value given refers to the isolated yield of purified material and is an average of two experiments. 
Table 2

Substrate Scope of Alkyl Pinacol Boronate Amination. ${ }^{a}$

\begin{tabular}{|c|c|c|}
\hline & $\begin{array}{c}\mathrm{MeONH}_{2} \text { (3 equiv) } \\
n \mathrm{BuLi} \text { (3 equiv) }\end{array}$ & \\
\hline$-B($ pin) & $\longrightarrow$ & $\mathrm{R}-\mathrm{NHBOC}$ \\
\hline$a-1$ & $\begin{array}{c}-78{ }^{\circ} \mathrm{C} \text { to } 60^{\circ} \mathrm{C}, 12 \mathrm{~h} ; \\
\text { then } \mathrm{Boc}_{2} \mathrm{O}\end{array}$ & $10-12$ \\
\hline
\end{tabular}

$$
\begin{aligned}
& \text { octyl-B(pin) }
\end{aligned}
$$

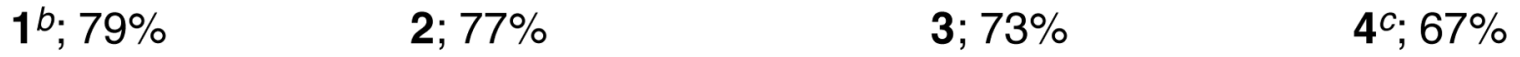<smiles>CCOC(CCCBr)OCC</smiles>

$5 ; 67 \%$

heptyl $\widehat{\curvearrowright}$ B(pin)

9; $82 \%$<smiles>N#CCCCBr</smiles>

$6 ; 36 \%$<smiles>O=[W](=O)(O)/C=C\CBr</smiles>

$10 ; 81 \%$<smiles>Br[Bi]([Hg])CCc1ccccc1</smiles>

$7 ; 77 \%$<smiles>BrC1CCCCC1Br</smiles>

$11 ; 68 \%$<smiles>C=CCC[BiH2]</smiles>

$8 ; 68 \%$<smiles>CC(C)(C)Br</smiles>

$12 ;<5 \%$

${ }^{a}$ Reactions were conducted as described in the text. The percent value given refers to the isolated yield of purified material and is an average of two experiments.

$b_{\text {This experiment was conducted on } 1 \text { gram scale. }}$

${ }^{c}$ An additional $15 \%$ yield of the bis(Boc)-protected amine could be isolated from this experiment. 


\section{Table 3}

Substrate Scope of Aryl Pinacol Boronate Amination. ${ }^{a}$

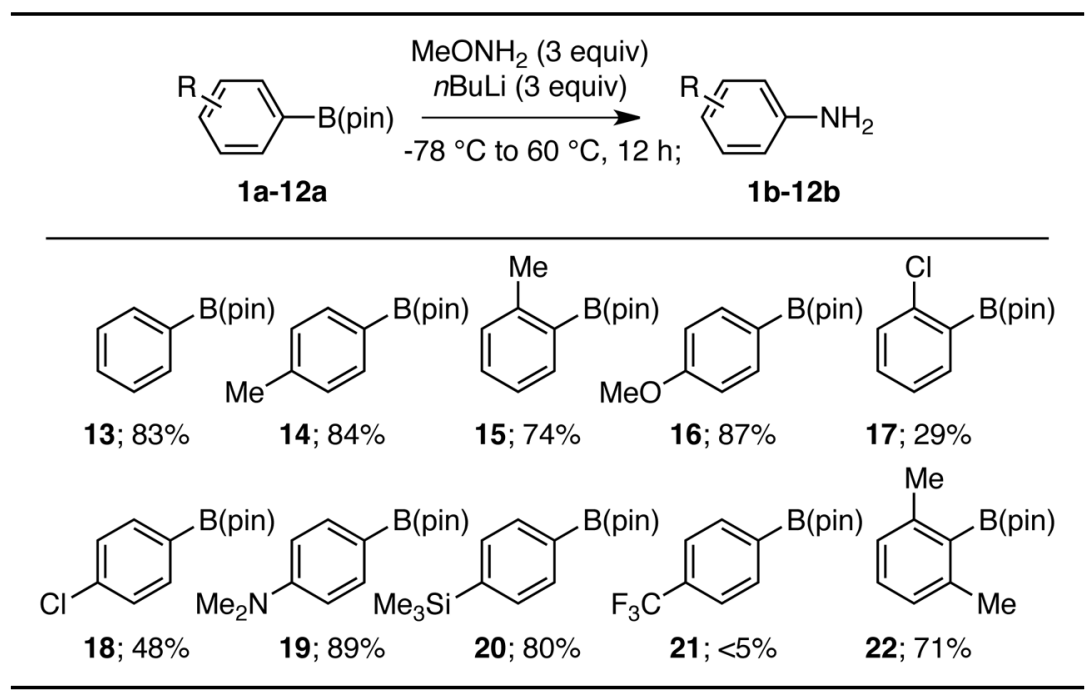

${ }^{a}$ Reactions were conducted as described in the text. The percent value given refers to the isolated yield of purified material and is an average of two experiments. 